\title{
Development and implementation strategy for the of product configuration systems in engineer-to-order companies
}

\author{
Kristjansdottir, Katrin; Shafiee, Sara; Hvam, Lars
}

Published in:

2016 IEEE International Conference on Industrial Engineering and Engineering Management (IEEM)

Link to article, DOI:

10.1109/IEEM.2016.7798190

Publication date:

2016

Document Version

Peer reviewed version

Link back to DTU Orbit

Citation (APA):

Kristjansdottir, K., Shafiee, S., \& Hvam, L. (2016). Development and implementation strategy for the of product configuration systems in engineer-to-order companies. In 2016 IEEE International Conference on Industrial Engineering and Engineering Management (IEEM) (pp. 1809-1813). IEEE. https://doi.org/10.1109/IEEM.2016.7798190

\section{General rights}

Copyright and moral rights for the publications made accessible in the public portal are retained by the authors and/or other copyright owners and it is a condition of accessing publications that users recognise and abide by the legal requirements associated with these rights.

- Users may download and print one copy of any publication from the public portal for the purpose of private study or research.

- You may not further distribute the material or use it for any profit-making activity or commercial gain

- You may freely distribute the URL identifying the publication in the public portal 


\title{
Development and Implementation Strategy for Product Configuration Systems in Engineer-to-Order Companies
}

\author{
K. Kristjansdottir ${ }^{1}$, S. Shafiee ${ }^{1}$, L. Hvam ${ }^{1}$ \\ ${ }^{1}$ Management Engineering, Technical University of Denmark, Kgs. Lyngby, Denmark \\ (katkr@dtu.dk, sashaf@,dtu.dk, lahv@dtu.dk)
}

\begin{abstract}
This paper will address how to develop a strategy when developing and implementing product configuration systems (PCSs) in engineer-to-order (ETO) companies. PCSs are often gradually implemented especially where there are complex products and processes in order to break down the overall project and reduce risk. This highlights the importance of having an overall strategy to guide the long-term development and implementation of PCSs. In this paper, guideline for making the strategy are provided and supplemented with examples based on a case study. The guideline includes the main objectives for the development and implementation process, PCSs to be used to support the sales and /or the engineering processes, more uniform IT support for making product configurations, combining output from different PCSs and finally integrations that includes both internal and external IT systems. Based on this an overview of how PCSs can support the overall configuration process can be generated.
\end{abstract}

Keywords - Product configuration system (PCS), Processes improvements, Strategy

\section{INTRODUCTION}

In response to increasing global competition, companies are pressured to improve the products' capabilities without compromising prices and time of deliveries [1]. To cope up with those challenges mass customization strategies are being applied to greater extent in companies. Product configuration systems (PCSs) have been defined as one of the key enabler to achieve the benefits from mass customization strategies [2] and represent some of the most successful applications of artificial intelligence [3]. PCSs are used to support design activities throughout the customization process, where a set of components along with their connections are pre-defined and where constrains are used to prevent infeasible configurations [4]. The literature describes various benefits that can be gained by implementing PCSs in terms of preservation of knowledge, use of fewer resources, optimization of products designs, less routine work, reduced lead-time, improved quality, improved certainty of delivery, reduced time for training new employees and increased customer satisfaction [1], [5][9].

Different strategies are required for PCS projects depending on the manufacturing strategy. In assembly-toorder (ATO) companies there is a more defined solution space and where modules / components are combined according to pre-defined constrains while in engineer-to order (ETO) companies there is more undefined solution space where the numbers of the possible configurations can be close to infinite [3]. The implementation of PCS in ETO companies is therefore more complex. To address those issues the focus of this study is on ETO companies and how an overall strategy can be generated to guide development and implementation processes for PCSs in such environment.

ETO companies can be defined by where the actual design of the product is done after receiving the order and before the production [10]. Due to the fact that the products are often and engineered for each customer, the sales process is more intensive and complex [11]. Furthermore, the information available in the sales phase can be limited, which increases uncertainties. As a result to complex nature of ETO companies, PCSs are often used for a design on a high level of abstraction, as a result of it being too time consuming to define the solution space on a more detailed level [12]. Finally, PCSs are typically used to support a specific part of the sales and engineering processes or a subset of the product family due to the complexity of processes and products. In these cases, PCSs are usually gradually implemented. Hence, there is a need for an overall strategy to guide development and the implementation process of PCSs especially in ETO companies.

\section{RESEARCH METHOOD}

The research method is structured in two phases. The first phase is dedicated to development of the guidelines aimed to support the overall strategy for the implementation and development processes of PCSs in ETO companies, which is based on both literature and experience. The second phase is concerned with the applying the proposed guidelines in an ETO company. For that purpose, a project team was formed, including two researchers from the Technical University of Denmark and experts from the company. Several workshops were held over the period where relevant stakeholders were involved in the development of the strategy. The results from that work are presented in the case study.

\section{LITERATURE STUDY}

\section{A. Application of PCSS in ETO companies}

PCS are be used to support the product configuration processes, which consist of set of activates that involves 
gathering information from customers and generation of all required product specifications [9], [11]. The product configuration process can be divided into sales and technical configuration processes [13]. The sales configuration process is concerned with identification of products that fulfills the customers' needs and determination of the main products' characteristics [13]. The technical configuration process is on the other hand concerned with generating the documentation for the product, based on the input gathered in the sales phase [13]. The end-user of the PCSs can either be the customer where the system allows him or her to configure the product e.g. over the internet and visualize the changes and the impact from specific selections, or the system can be used as an internal tool to support the company's employees in the product configuration process [3].

In ETO companies, the configuration process is more complex than in ATO companies due to a less defined solution space [3]. Therefore, PCSs in ETO companies are normally used for design on a high level of abstraction, as it can be extremely time consuming to define the solution space on a more detailed level [14]. This is opposite to ATO companies, where there is a more defined solution space for different product configurations, which enables detailed designs to be generated in the sales phase [1]. Therefore, in ATO companies, PCSs can be used to generate a quotation for a more detailed designs than in ETO companies [15]. The main output types generated by the PCSs can be used to divide the process of generating the products' specifications into three phases, which are the initial specification, further product specification, and quote creation [14]. In Fig. 1, it is illustrated how the level of details for the PCSs can be determined based on output generated by the PCSs.

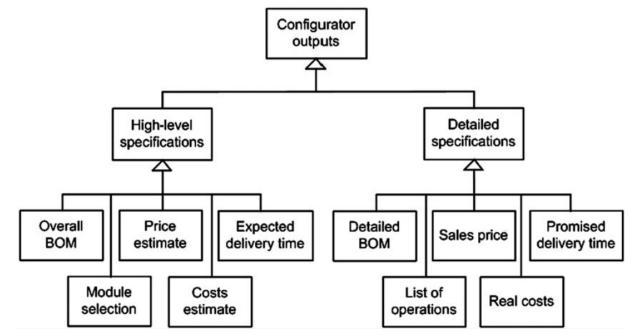

Fig. 1 The main output from the PCSs and level of detail required [14]

\section{B. Structure of the PCSs and integrations}

The underlying IT structure of a PCS consists of configuration knowledge representation and reasoning, conflict detection and diagnosis, and user interface [16]. The most fundamental technical component of the PCS is defined as the knowledge base, which represent both the actual database and the configuration logic [3]. The configuration processes for complex products can be overwhelming in terms of different solutions that can be chosen from, which can result in optimal solutions not being chosen [17], designing a recommendation system in the IT architecture is therefore suggested. The recommendation technologies can then be integrated to support the end-user in the configuration process [18].

PCSs can be applied as standalone software, data integrative and application-integrative configurators [3]. Data integrated PCSs can be used to avoid data redundancy and finally application integrated PCSs allows communication across different applications e.g. CAD drawings can be generated from the output of the PCS [3]. In terms of data integration for PCSs, common sources can be found for master data in ERP systems that often define a production relevant view of material that is required for the assembly process, product data management (PDM) and product lifecycle management (PLM) systems which are used to maintain production relevant data, and finally product information management (PIM) systems that are used to maintain sales-relevant data [19]. PCSs can also be integrated to suppliers systems in order to retrieve the required data from them in the configuration processes [20]. Furthermore, different PCSs can be integrated for example in terms of sales and technical PCSs to increase the level of automation in the overall process [9].

\section{Development strategies for PCS projects}

Haug et al. [21] define strategies for PCSs in ETO companies, where the focus is on involvement of different specialist in the PCSs development and the implementation process. Hvam et al. [1] provide a 7 phases framework, which includes analysis and redesign of the business processes, modeling of the product range, chose of PCSs software, modeling and implementation and maintenance plan. Forza and Salvador [9] provide a guidelines for implementation of a PCSs, which include benefits and cost analyzes, planning of the implementation processes and how to execute the implementation aligned with best practice. Finally, Felfernig et al. [22] propose a development strategy based on the standard UML design language to develop the knowledge base and cope up with increasing complexity of the knowledge base. The three main components of the configuration environment are defined as the knowledge acquisition, configuration and reconfiguration and where diagnoses are proposed at each stage [22].

The previous researchers describe different steps related to strategic decisions to be taken at companies, but provide guidelines to make a comprehensive strategy to guide the development and the implementation for PCSs.

\section{THE STRATEGY FOR APPLICATIONS OF PCSS IN ETO CONPANIES}

In order to guide the strategy for development and implementation of PCS in ETO companies, this research proposes guidelines demonstrating alternative ways to apply the systems. By having an overall strategy for the implementation process, sub-optimization of individual process should be avoided and different stakeholders are more likely to have a common understanding of the 
overall aim. Following are the main areas that have to be taken into the account.

- Objectives for the development and implementation [1], [5]-[9]

- $\quad$ PCSs to be used in the sales or the engineering processes (sales and technical PCSs) [13]

- Level of detail and completeness [1], [14], [15]

- $\quad$ More uniform IT support for generating product configurations [1]

- $\quad$ Output generated from PCSs operated in different departments e.g. output is combined from different PCSs on equipment level and combined into project / plant [1], [9]

- Integrations - which includes both internal and external IT systems [3], [17]-[20]

- Overview of how PCSs can support the product configuration process

First, in order to guide the development and the implementation processes, clear objectives have to be defined. Next step is concerned with identifying application areas to support both the sales and engineering processes. In this step, the level of detail and completeness is also determined. There is often a trade-off between the level of detail and completeness, which is the number of components/modules included in the system. Sales PCSs often include variety of product on a high level of detail while technical PCSs have greater level of detail but low completeness as a result of being designed to support specific product.

As a result of highly complex products, PCS are usually implemented gradually in ETO companies. Therefore, consideration of having uniform IT support for generating the specifications and combining different PCSs across departments is elaborated. Finally, the dependency on retrieving information from both internal and external IT systems is very high. Internal IT systems can include ERP systems, CAD systems, calculations and simulations software and etc. In terms of integration to external IT systems, it can interpret e.g. as retrieving information that is needed in the configuration processes from suppliers' database.

By taking into account these areas to guide the development and the implementation process for PCSs, an overall overview of how different process can be supported by PCSs can be generated.

\section{CASE STUDY}

The case company is a world leader in catalysts and surface science. The company offers great variety of catalyst and complete range of proprietary equipment, spare parts and consumables. The PCS concept was first introduced at the company 2012 where the main focus was set on supporting the sales processes in the different business units (BUs) at the company. In the year 2016, five PCSs were in use at the company and three under development. The application areas of the systems cover some of the main products categorization offered by the company, such as catalysts, equipment and process plants. The implementation of PCSs at the company has proven its usability in terms of numerous benefits. The approach to expand the configuration area has primarily been focused on the implementation of new configurators with little considerations of making an overall optimized workflow. This approach served its purpose to quickly establish the area, and demonstrate the benefits that can be achieved by utilizing PCSs. However, a more holistic overview of potential areas for the development and the implementation had to be established. The strategy will therefore focus on achieving an overall overview to guide the future development and the implementation process at the company.

\section{A. Objectives for the development and the implementation}

The main objectives at the company are described in terms of reduced routine work, decreased lead-time to generate proposals and product specifications, increase hit rate as a result to shorter lead-time, improved quality and empowerment of the global sales offices to generate proposals. The importance of the objective can though differ from project to project. For instance, for a process plant with very low sale rate, the objective of investing in PCS is to empower all the regional offices around the world and extracting all implicit needed knowledge from employees and turn them to be more explicit are more the most important objectives.

\section{B. Configuration systems to be used in the sales or the engineering processes}

The previous focus at the company has been preliminary on developing PCSs to support the sales processes in the different BUs. However, given the increased maturity of the configuration area at the company, an investigation of how the engineering processes can be supported has been initiated. The differences between the sales and the technical PCSs are listed in Table I.

TABLE I

PCSs TO SUPPORT THE SALES AND ENGINEERING PROCESS

\begin{tabular}{ll}
\hline Sales PCS & Technical PCS \\
\hline Support: The sales process & Support: The engineering process \\
$\begin{array}{l}\text { Level of detail: Minimum level } \\
\text { of engineering detail (mostly } \\
\text { commercial) }\end{array}$ & $\begin{array}{l}\text { Level of detail: High level of } \\
\text { detail including engineering } \\
\text { specific detail }\end{array}$ \\
$\begin{array}{l}\text { Output: Proposal creation, } \\
\text { including cost estimation }\end{array}$ & $\begin{array}{l}\text { Output: Engineering } \\
\text { documentation, including 3D } \\
\text { models }\end{array}$ \\
\hline
\end{tabular}

Sales and technical PCSs are not mutually exclusive. They may even be used in conjunction with one another as shown in the Fig. 2 where the output of the sales PCS can be used as input for the technical PCS. 


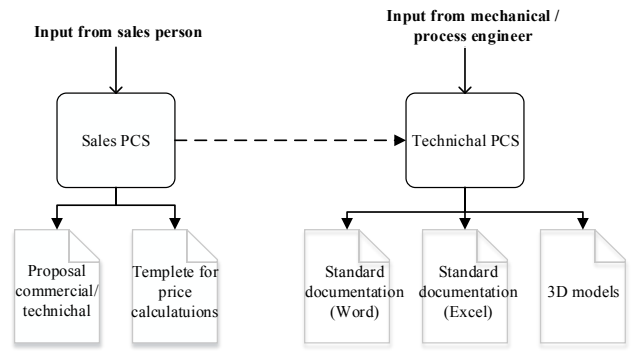

Fig. 2. The interaction between sales and technical PCS

By operating both sales and technical PCSs, it enables the mechanical/process engineers to base their work on the output from the sales PCS, and to work with the data inside the technical PCS. This optimization of the workflow means that data relevant for the configuration is stored in just one system. This system then forms the platform in a way which both sales persons and mechanical/process engineers can work with. Hence, with the above-mentioned example, the introduction of more detailed technical configurators, capable of automating standard engineering processes, are presented to increase the benefits of configuration concepts by adding to the possible output documents of the existing sales PCSs. Most PCSs can have this dual functionality. However, there may be cases where it is not beneficial to combine sales and technical PCSs, which is why the identification of new configurators is split into the two main categories - sales PCSs and technical PCSs.

\section{More uniform IT support for generating product configurations}

This implies more standardized way of applying tools and software needed to generate the different product specifications. In the case company, this implies the replacement of Excel based in-house developed tools with PCSs. Furthermore, this enables more uniform product specifications, which are expected to improve the overall quality and by using the same tools helps to standardize the workflow across the departments.

\section{Combining output from different PCSs}

Having increased number of PCSs in operation in the different departments, it opens up to the possibility of combining the output based on input from individual PCS to cover complete projects / plants as demonstrated in Fig. 3. With this setup, the sales department can generate proposals e.g. by taking input directly from the relevant departments instead of receiving the input via e-mail and copy-pasting it in the Word-files. This implies more standardized procedure across the departments where more structured approach is provided for the knowledge sharing.

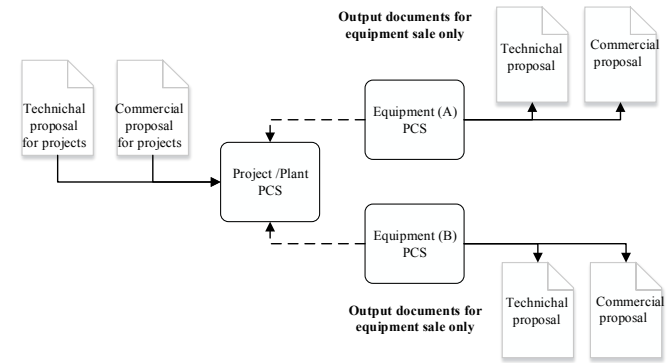

Fig. 3. Achieving synergy effects by generating documents from information across departments PCSs

E. Integrations, which includes both internal and external IT systems

Several software applications are used at the company for complex calculations and simulations. These software applications play a critical role as they provide information both for the sales and engineering processes. Therefore, integrations to these systems were established with the first PCSs developed at the company. The company's ERP system contains information critical to the configuration process related to customers' information and cost prices. Integrating the PCS and CAD system could enable the possibility of generating 3D models based on the output generated of the technical PCS. Finally, there are various parts bought from suppliers, therefore there is a need to retrieve information from them in the configuration process. By integrating the internal PCSs used at the case company to the suppliers system, it can be ensured that the information is up-todate in PCSs without the need for manual adjustments.

\section{F. Overview of how PCSs can support the product configuration process}

In order to support the business to the greatest extent via PCSs development and implementation, a holistic view is needed for each of the BUs. Therefore, visualizations of the how the PCSs can support the different BUs were generated, which take into account the abovementioned focused areas. In Fig. 4 an example is provided for one of the BUs where the different development concepts are applied.

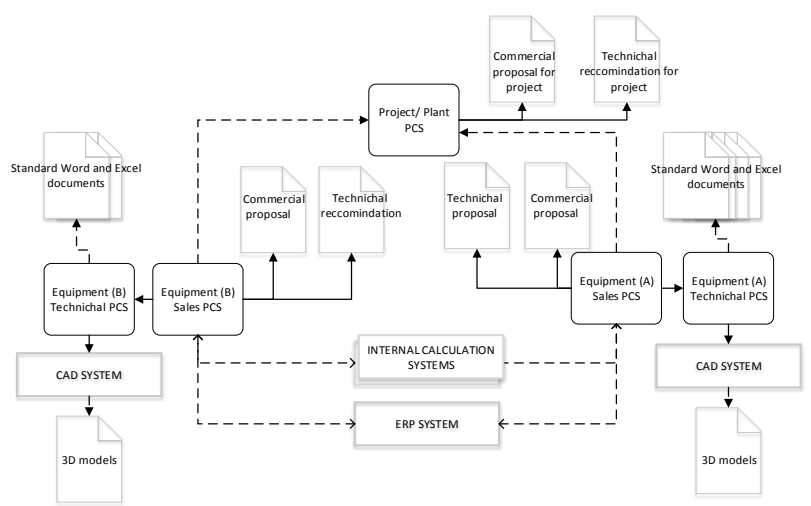

Fig. 4. Simplified overview how the sales and engineering processes can be supported by PCS and interaction with other IT systems

VI. DISCUSSION AND CONCLUSION 
The main focus of this article is to provide guidelines for an overall strategy to guide the development and the implementation processes for PCSs in ETO companies. Due to highly complex products and processes, PCSs are usually gradually implemented, which highlights the importance of having an overall strategy to guide the processes. The literature describes different development strategies, however none of them specifies how to make an overall strategy to guide the development and the implementation process for PCSs in ETO companies. This research explores that research opportunity by providing foundation to guide the strategy work in terms of different applications areas.

In order to achieve sustainable growth of the PCSs area at the case company, further consideration of testing, maintenance activities and user support has to be taken into considerations. Furthermore, in order to secure the capabilities of the configuration team to follow the strategy through suggestions of the most applicable setup of the team are elaborated. Governance structure and commitment of the business resources are also defined. Finally, collaboration with externals actors is listed in order to make share knowledge across ETO companies and to be up-to-date regarding the newest developments in the area.

The results indicate the development of the strategy has enabled different stakeholders at the company to have more common understanding of the overall aim with PCS development and the implementation. Furthermore, it should help companies in the strategic planning and to justify the investment in the PCSs projects. Finally, required resources, benefits and outputs are determined as well as all requirements are expressed before starting the actual development of the PCS.

In terms of further studies several ETO companies have been identified in order to make further testing of the guidelines to increase the generalizability. Furthermore, these guidelines could be tested in other types companies to verify it is not limited only to ETO companies.

\section{REFERENCES}

[1] L. Hvam, J. Riis, and N. H. Mortensen, Product customization. Berlin Heidelberg: Springer, 2008.

[2] B. J. Pine II, B. Victor, and A. C. Boynton, "Making mass customization work," Harv. Bus. Rev., vol. 71, no. 5, 1993.

[3] T. Blecker, N. Abdelkafi, G. Kreutler, and G. Friedrich, "Product configuration systems: state of the art, conceptualization and extensions," in Proceedings of the Eight Maghrebian Conference on Software Engineering (MCSEAI 2004), 2004, pp. 25-36.

[4] A. Felfernig, G. E. Friedrich, and D. Jannach, "UML as Domain Specific Language for the Construction of Knowledge-based Configuration Systems," Int. J. Softw. Eng. Knowl. Eng., vol. 10, no. 4, pp. 449-469, 2000.

[5] F. Piller, K. Moeslein, and C. Stotko, "Does mass customization pay? An economic approach to evaluate customer integration," Prod. Plan. Control, 2004.

[6] A. Felfernig, D. Jannach, and M. Zanker, "Contextual diagrams as structuring mechanisms for designing configuration knowledge bases in UML," «UML》 2000-The Unified Model. 2000.

[7] L. Ardissono, A. Felfernig, G. Friedrich, A. Goy, D. Jannach, G. Petrone, R. Schäfer, and M. Zanker, "A framework for the development of personalized, distributed web-based configuration systems," AI Mag., vol. 24, no. 3, pp. 93 - 108, 2003.

[8] L. L. Zhang, "Product configuration: a review of the state-of-the-art and future research," Int. J. Prod. Res., vol. 52, no. 21, pp. 6381-6398, 2014.

[9] C. Forza and F. Salvador, Product information management for mass customization. New York: Palgrave Macmillan, 2007.

[10] F. Caron and A. Fiore, “"Engineer to order' companies: how to integrate manufacturing and innovative processes," Int. J. Proj. Manag., vol. 13, no. 5, pp. 313-319, 1995.

[11] C. Forza and F. Salvador, "Managing for variety in the order acquisition and fulfilment process: The contribution of product configuration systems," Int. J. Prod. Econ., vol. 76, no. 1, pp. 87-98, 2002.

[12] A. Haug, L. Hvam, and N. H. Mortensen, "The impact of product configurators on lead times in engineeringoriented companies," Artif. Intell. Eng. Des. Anal. Manuf., vol. 25, no. 02, pp. 197-206, 2011.

[13] C. Forza and F. Salvador, "Application support to product variety management," Int. J. Prod. Res., vol. 46, no. 3, pp. 817-836, 2008.

[14] A. Haug, L. Hvam, and N. H. Mortensen, "The impact of product configurators on lead times in engineeringoriented companies," Artif. Intell. Eng. Des. Anal. Manuf., vol. 25, no. 02, pp. 197-206, 2011.

[15] L. Hvam, "Mass Customization in the electronics industry: based on modular products and product configuration," Int. J. Mass Cust., vol. 1, no. 4, pp. 410 $-426,2006$.

[16] A. Felfernig, L. Hotz, C. Bagley, and J. Tiihonen, Knowledge-based configuration: From research to business cases. Morgan Kaufman, 2014.

[17] J. Tiihonen and A. Felfernig, "Towards recommending configurable offerings," Int. J. Mass Cust., vol. 3, no. 4, pp. 389-406, 2010.

[18] J. Tiihonen, A. Felfernig, and M. Mandl, "Personalized configuration. Knowledge-based Configuration-From Research to Business Cases," in Knowledge-based Configuration: From Research to Business Cases, Morgan Kaufman, 2014.

[19] T. Krebs, "encoway," in Knowledge-based configuration: From research to business cases, A. Felfernig, L. Hotz, C. Bagley, and J. Tihonen, Eds. Morgan Kaufman, 2014, pp. 271-279.

[20] L. Ardissono, A. Felfernig, G. Friedrich, A. Goy, D. Jannach, G. Petrone, R. Schafer, and M. Zanker, "A Framework for the Development of Personalized, Distributed Web-Based Configuration Systems," $A I$ Magazine, vol. 24, no. 3. p. 93, 2003.

[21] A. Haug, L. Hvam, and N. H. Mortensen, "Definition and evaluation of product configurator development strategies," Comput. Ind., vol. 63, no. 5, pp. 471-481, 2012.

[22] A. Felfernig, G. Friedrich, and D. Jannach, "Conceptual modeling for configuration of mass-customizable products," Artif. Intell. Eng., vol. 15, no. 2, pp. 165$176,2001$. 